\title{
PENGARUH PENAMBAHAN PECAHAN KERAMIK PADA PEMBUATAN PAVING BLOCK DITINJAU DARI NILAI KUAT TEKAN
}

\author{
Aulia Zastavia Putri*, Imastuti** \\ *Mahasiswi Program Studi Teknik Sipil, Fakultas Teknik Universitas Katolik Soegijapranata \\ **Mahasiswi Program Studi Teknik Sipil, Fakultas Teknik Universitas Katolik \\ Soegijapranata
}

\begin{abstract}
ABSTRAK
Paving block merupakan salah satu bahan bangunan yang digunakan sebagai alternative perkerasan jalan. Bahan penyusun dari paving block adalah semen, pasir dan air dengan atau tanpa bahan tambah lainnya. Bahan tambah yang digunakan dapat berupa limbah atau sisa bahan bangunan yang tidak digunakan. Penggunaan limbah bertujuan untuk meningkatkan mutu paving block dan memanfaatkan limbah secara optimal. Limbah keramik lantai merupakan contoh limbah yang banyak ditemukan di sekitar lingkungan. Oleh sebab itu, perlu diadakan penelitian untuk mengetahui pengaruh nilai kuat tekan paving block akibat penambahan pecahan keramik. Dalam penelitian ini digunakan perbandingan semen dan pasir adalah 1:5 dengan presentase pecahan keramik 0\%, 5\%, 10\% dan 15\% dari berat pasir. Nilai f.a.s yang digunakan adalah 0,3. Hasil pengujian nilai kuat tekan pada prensentase $0 \%$ adalah $424,167 \mathrm{~kg} / \mathrm{cm}^{2}$, nilai kuat tekan pada prensentase $5 \%$ adalah $436,667 \mathrm{~kg} / \mathrm{cm}^{2}$, nilai kuat tekan pada prensentase $10 \%$ adalah $465 \mathrm{~kg} / \mathrm{cm}^{2}$ dan nilai $\mathrm{kuat}$ tekan pada prensentase $15 \%$ adalah $523,333 \mathrm{~kg} / \mathrm{cm}^{2}$. Nilai kuat tekan terting gi pada pecahan keramik sebanyak $15 \%$ yaitu $523,333 \mathrm{~kg} / \mathrm{cm}^{2}$. Peningkatan kuat tekan terjadi sebesar 23,38\% dari presentase pecahan keramik 0\% terhadap pecahan keramik $15 \%$. Nilai kuat tekan tersebut memenuhi persyaratan standar mutu kelas I/A dengan kuat tekan rata-rata 400 $\mathrm{kg} / \mathrm{cm}^{2}$ dan minimal $350 \mathrm{~kg} / \mathrm{cm}^{2}$. Dari hasil penelitian, dapat disimpulkan bahwa pecahan keramik dapat meningkatkan mutu paving block seiring dengan penambahan presentase pecahan keramik.
\end{abstract}

Kata kunci: paving block, kuat tekan, pecahan keramik

\section{PENDAHULUAN}

\subsection{Latar Belakang}

Paving block merupakan suatu bahan bangunan yang kerap kali digunakan sebagai alternatif perkerasan jalan. Penggunaan paving block semakin meningkat seiring banyaknya program pavingisasi di Kota Semarang. Program pavingisasi dilakukan untuk pembangunan dan perbaikan lingkungan permukiman. Pavingisasi pada tahun 2014 mencapai $3.780 \mathrm{~m}^{2}$, sedangkan pada tahun 2015 mencapai $4.307 \mathrm{~m}^{2}$ dengan tebal paving block sebesar $6 \mathrm{~cm}$ (Pemerintah Kota Semarang, 2014).

Bahan penyusun paving block adalah semen, pasir dan air dengan atau tanpa bahan tambah lainnya. Semakin sedikit jumlah pasir semakin baik mutu yang dihasilkan. 
Penambahan bahan tambah juga dapat digunakan sebagai alternatif untuk meningkatkan mutu paving block. Banyak usaha untuk meningkatkan mutu paving block, terlihat dari banyaknya penelitian yang dilakukan dengan inovasi menggunakan limbah sebagai bahan tambah.

Limbah keramik lantai merupakan salah satu jenis limbah sisa bahan konstruksi yang tidak digunakan. Pemanfaatan pada limbah tersebut kurang optimal, sehingga limbah tersebut banyak ditemukan pada lingkungan sekitar. Oleh sebab itu, diperlukan adanya upaya untuk mengurangi limbah keramik dengan cara memanfaatkan penggunaan limbah secara optimal. Upaya tersebut dapat berupa penelitian untuk meningkatkan mutu paving block. Hasil dari penelitian ini diharapkan dapat digunakan sebagai salah satu upaya untuk memanfaatkan limbah keramik sebagai bahan tambah dalam pembuatan paving block.

\subsection{Tujuan Penelitian}

Tujuan dari penelitian ini adalah:

1. Mengetahui komposisi dan karakteristik bahan penyusun paving block

2. Mengetahui nilai kuat tekan paving block yang diberi penambahan pecahan keramik dengan perbandingan komposisi semen : pasir sebesar $1: 5$, dan dengan persentase pecahan keramik sebanyak $0 \%, 5 \%, 10 \%, 15 \%$, serta dalam umur pengujian 7,14 , dan 28 hari

3. Mengetahui nilai ekonomis paving block yang diberi penambahan pecahan keramik.

\section{TINJAUAN PUSTAKA}

\subsection{Paving Block}

Paving block merupakan suatu jenis bahan bangunan yang terbuat dari campuran semen atau bahan perekat sejenisnya, air, agregat berupa abu batu atau pasir, dengan ataupun tanpa bahan tambahan lain (SNI 03-0691, 1996).

\subsection{Material Penyusun Paving Block}

\section{a. Semen Portland (PC)}

Semen Portland memiliki kegunaan sebagai pengikat butiran agregat hingga menjadi padat, serta mengisi rongga udara di antara butiran agregat dalam pada paving block.

b. Agregat Halus

Agregat halus atau pasir merupakan butiran mineral keras yang berbentuk hampir bulat dan tajam, serta sebagian besar berukuran maksimum 4,76 mm (SNI 03-6820, 2002). Agregat halus berguna sebagai bahan pengisi dalam penyusunan paving block 
yang dapat menambah kekuatan, meminimalisir penyusutan, serta mengurangi penggunaan semen.

c. Air

Air merupakan salah satu unsur yang penting dan sangat berpengaruh dalam pembuatan paving block, karena bila kadar air yang digunakan terlalu tinggi dapat mengurangi nilai kuat tekan dari paving block. Jumlah air yang digunakan untuk proses pembuatan paving block harus cukup, supaya material penyusun paving block dapat merekat dengan sempurna.

d. Keramik

Keramik merupakan salah satu bahan yang digunakan untuk melapisi lantai atau dinding dalam suatu konstruksi, serta terbuat dari tanah liat yang dibakar dengan temperatur yang tinggi.

\subsection{Kuat Tekan}

Pada proses pembuatan paving block, perlu dilakukan suatu pengujian untuk menentukan mutu dari paving block yang dihasilkan, salah satunya yaitu uji kuat tekan. Kuat tekan yakni kemampuan beton dalam menerima gaya tekan persatuan luas. Nilai kuat tekan menunjukkan mutu dari suatu struktur, semakin tinggi nilai kuat tekannya semakin tinggi pula mutu yang didapatkan (Mulyono, 2004).

\section{METODE PENELITIAN}

\subsection{Lokasi Penelitian}

a. Pemeriksaan dan pengujian bahan dilakukan di Laboratorium Bahan Bangunan Unika Soegijapranata Semarang.

b. Pembuatan benda uji dilakukan di Prokon Concrete Industry yang beralamat Jl. Plamongan Sari RT. 03 RW. 03 Pucang Gading, Semarang.

c. Pengujian kuat tekan paving block dilakukan di Laboratorium Bahan Bangunan Unika Soegijapranata Semarang.

\subsection{Benda Uji}

Tabel 1 Jumlah Benda Uji Paving Block

\begin{tabular}{|c|c|c|c|c|}
\hline \multirow{2}{*}{$\begin{array}{c}\text { Umur } \\
\text { Pengujian }\end{array}$} & \multicolumn{4}{|c|}{ Kadar Pecahan Keramik } \\
\cline { 3 - 5 } & $0 \%$ & $5 \%$ & $10 \%$ & $15 \%$ \\
\hline 7 hari & 3 buah & 3 buah & 3 buah & 3 buah \\
\hline 14 hari & 3 buah & 3 buah & 3 buah & 3 buah \\
\hline
\end{tabular}




\begin{tabular}{|l|l|l|l|l|}
\hline 28 hari & 3 buah & 3 buah & 3 buah & 3 buah \\
\hline
\end{tabular}

Tabel 2 Komposisi Campuran Benda Uji Paving Block

\begin{tabular}{|c|c|c|c|c|c|}
\hline $\begin{array}{c}\text { Perbandingan } \\
\text { Pc : Ps : Pecahan } \\
\text { Keramik }\end{array}$ & $\begin{array}{c}\text { Kadar } \\
\text { Pecahan } \\
\text { Keramik }\end{array}$ & fas & $\begin{array}{c}\text { Kebutuhan } \\
\text { Pasir } \\
(\mathrm{kg})\end{array}$ & $\begin{array}{c}\text { Kebutuhan } \\
\text { Semen } \\
(\mathrm{kg})\end{array}$ & $\begin{array}{c}\text { Kebutuhan } \\
\text { Keramik } \\
(\mathrm{kg})\end{array}$ \\
\hline $1: 5: 0$ & $0 \%$ & 0,3 & 2,1 & 0,42 & 0 \\
\hline $1: 4,75: 0,25$ & $5 \%$ & 0,3 & 2 & 0,42 & 0,11 \\
\hline $1: 4,5: 0,5$ & $10 \%$ & 0,3 & 1,9 & 0,42 & 0,21 \\
\hline $1: 4,25: 0,75$ & $15 \%$ & 0,3 & 1,8 & 0,42 & 0,32 \\
\hline
\end{tabular}

\subsection{Bagan Alir Penelitian}

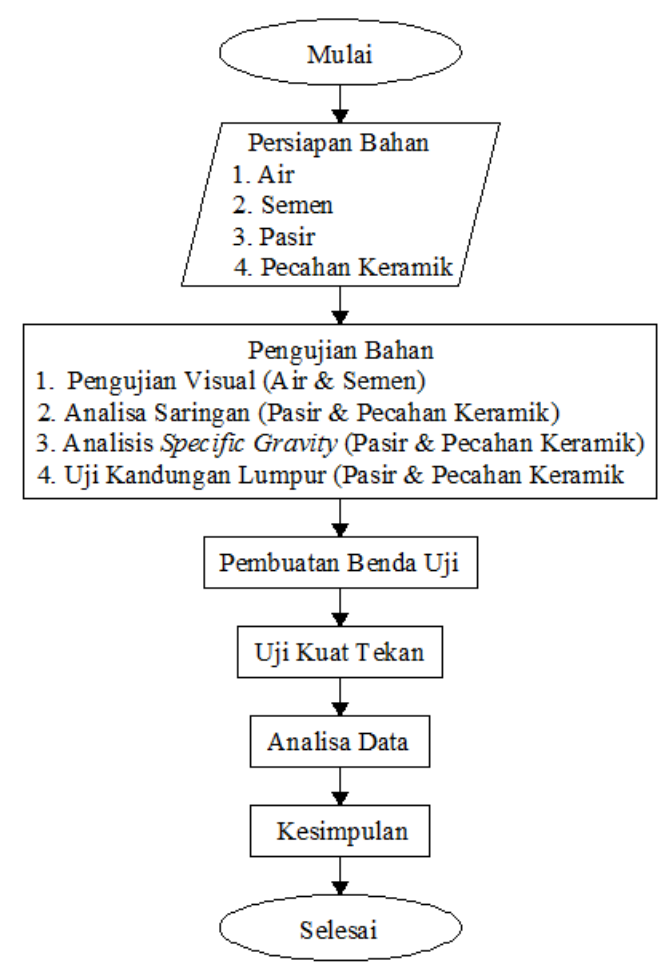

\section{HASIL PENELITIAN DAN PEMBAHASAN}

\subsection{Hasil Pengujian Bahan}

a. Air

Air yang digunakan dalam proses pembuatan paving block adalah air yang berasal dari sumur yang terletak di dalam area pabrik Prokon Concrete Industry. Air tersebut 
merupakan air yang setiap harinya digunakan oleh pabrik tersebut untuk membuat paving block. Pemeriksaan air dilakukan secara visual atau dengan dilihat saja yakni air harus bersih, tidak mengandung lumpur, minyak dan garam.

b. Semen

Semen yang digunakan dalam proses pembuatan paving block ini adalah semen Portland jenis I bermerk Semen Gresik dalam ukuran $50 \mathrm{~kg} / \mathrm{sak}$, dan merupakan semen yang digunakan oleh Prokon Concrete Industry dalam kegiatan produksinya. Pemeriksaan dilakukan secara visual pula yaitu semen dalam keadaan baik dan tidak terdapat gumpalan pada butirannya.

c. Pasir

Pengujian yang pertama dilakukan pada pasir yakni analisa specific gravity dan penyerapan, dimana hasil yang diperoleh untuk apparent specific gravity sebesar 2,79, untuk bulk specific gravity dan saturated surface dry (SSD) sebesar 2,77, serta nilai penyerapan air sebesar $0,32 \%$. Nilai analisa specific gravity tersebut masuk dalam syarat sebesar 2,4 - 2,9 sesuai PUBI, 1982. Pengujian yang dilakukan selanjutnya yakni analisa saringan, dengan hasil pengujian yang didapatkan sebesar 2,65. Nilai modulus kehalusan yang diperoleh sesuai dengan syarat yang ditentukan yaitu antara 2 - 3 (SNI 03-6820, 2002). Pengujian terakhir yakni kadar lumpur pada pasir, dan didapatkan hasil sebesar $5,31 \%$. Nilai tersebut lebih besar dari syarat yang ditentukan yakni maksimal sebesar $5 \%$, sehingga pasir tersebut harus dicuci terlebih dahulu sebelum digunakan.

d. Pecahan Keramik

Pengujian yang dilakukan pertama kali pada pecahan keramik yakni analisa specific gravity dan penyerapan, dimana hasil yang diperoleh untuk apparent specific gravity sebesar 2,4, untuk bulk specific gravity sebesar 2,11, saturated surface dry (SSD) sebesar 2,22 , serta nilai penyerapan air sebesar 2,22\%. Meskipun ada beberapa nilai yang tidak memenuhi syarat, pecahan keramik masih termasuk dalam agregat berukuran normal. Pengujian yang dilakukan selanjutnya yakni analisa saringan, dengan hasil pengujian yang didapatkan sebesar 2,9 dan sudah sesuai dengan syarat. Pengujian ketiga yakni kadar lumpur pada pecahan keramik, dan didapatkan hasil sebesar 1,63\%, dimana nilai sudah sesuai dengan syarat yang ditetapkan.

\subsection{Hasil Pengujian Kuat Tekan Paving Block}

Sampel benda uji paving block yang telah berumur 7, 14, dan 28 hari kemudian diuji kuat tekannya. Pengujian kuat tekan dilakukan di Laboratorium Bahan Bangunan Universitas 
Katolik Soegijapranata dengan menggunakan compression test machine. Nilai hasil kuat tekan yang dihasilkan dari proses pengujian tersebut didapat dari beban yang dapat ditahan oleh paving block dibagi dengan luas permukaannya.

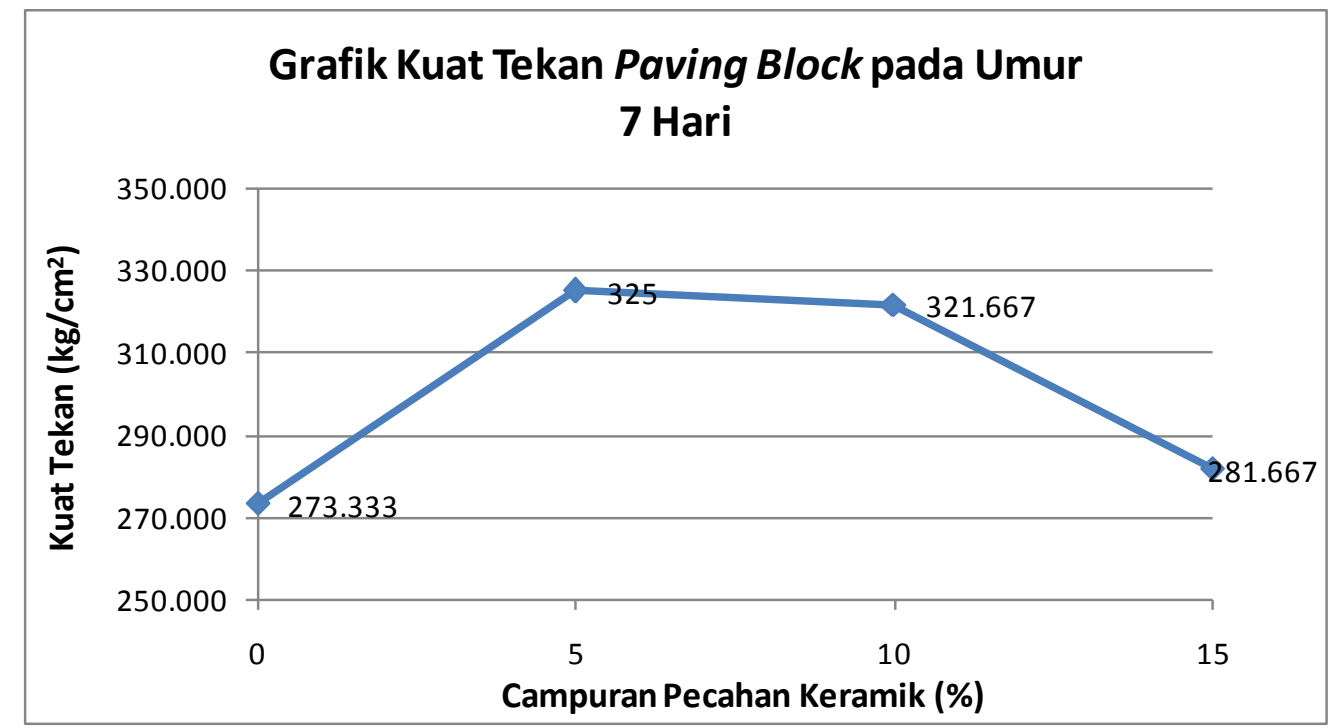

Gambar 1 Grafik Nilai Kuat Tekan Paving Block pada Umur 7 Hari

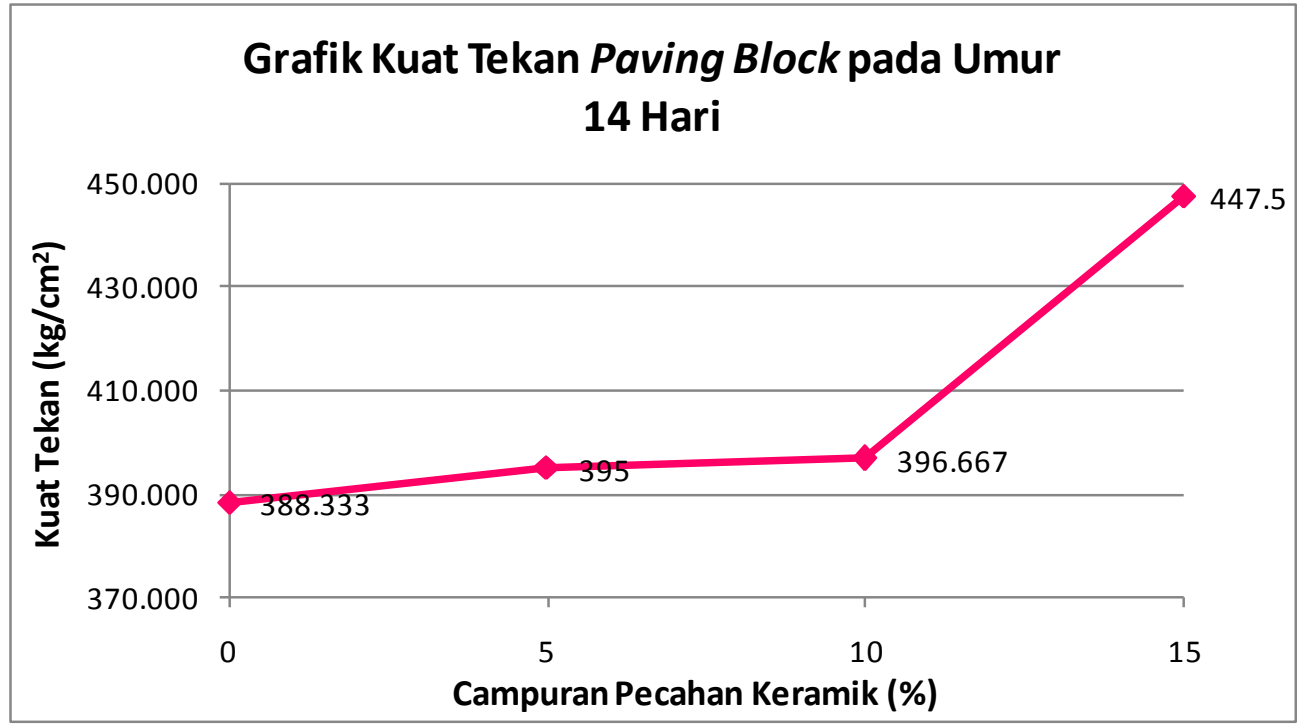

Gambar 2 Grafik Nilai Kuat Tekan Paving Block pada Umur 14 Hari 


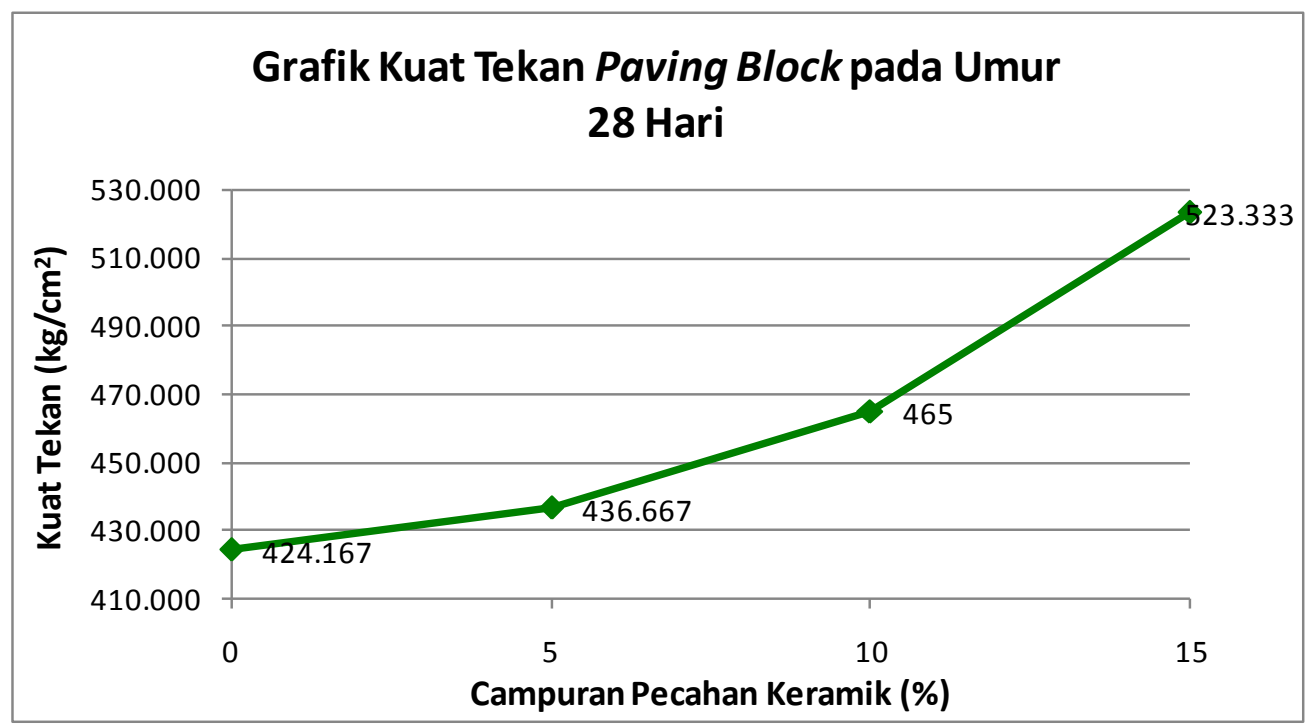

Gambar 3 Grafik Nilai Kuat Tekan Paving Block pada Umur 28 Hari

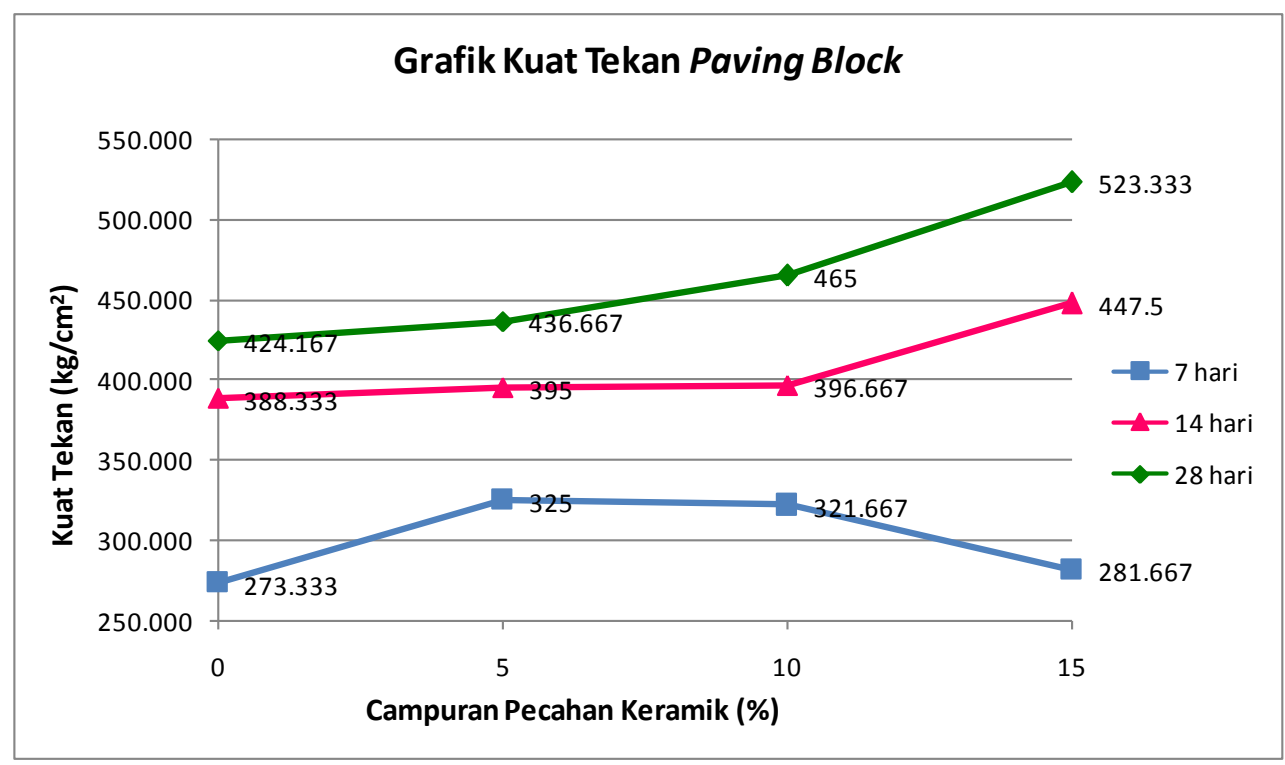

Gambar 4 Grafik Nilai Kuat Tekan Paving Block dengan Campuran Pecahan Keramik

Nilai kuat tekan paving block mengalami peningkatan seiring dengan penambahan presentase campuran pecahan keramik. Hal itu dapat dilihat pada paving block dengan umur 14 dan 28 hari. Nilai kuat tekan yang diperoleh mengalami kenaikan pada paving block yang diberi campuran pecahan keramik terhadap paving block yang tidak diberi pecahan keramik. Tetapi, pada paving block dengan umur 7 hari mengalami penurunan saat diberi penambahan campuran pecahan keramik sebanyak $10 \%$ dan 15\%. Nilai kuat tekan paving block tertinggi berada pada paving block dengan umur 28 hari yang diberi penambahan campuran pecahan keramik sebanyak $15 \%$ yaitu $523,333 \mathrm{~kg} / \mathrm{cm} 2$. Sedangkan, nilai kuat tekan paving block 
terendah yaitu $424,167 \mathrm{~kg} / \mathrm{cm}^{2}$ pada paving block yang tidak diberi campuran pecahan keramik. Berdasarkan SNI 03-0691-1996, nilai kuat tekan tersebut dapat digunakan pada perkerasan jalan dengan rata-rata kuat tekan $400 \mathrm{~kg} / \mathrm{cm}^{2}$ dan minimal kuat tekan $350 \mathrm{~kg} / \mathrm{cm}^{2}$.

\subsection{Nilai Ekonomis Paving Block}

Tabel 3 Perbandingan Harga Paving Block Produk Penelitian dengan Produk di Pasaran

Kota Semarang

\begin{tabular}{|c|c|c|c|c|c|c|}
\hline \multirow[b]{2}{*}{ No. } & \multirow[b]{2}{*}{$\begin{array}{c}\text { Kadar } \\
\text { Pecahan } \\
\text { Keramik }\end{array}$} & \multirow[b]{2}{*}{$\begin{array}{c}\text { Nilai } \\
\text { Kuat } \\
\text { Tekan } \\
\left(\mathrm{kg} / \mathrm{cm}^{2}\right)\end{array}$} & \multicolumn{4}{|c|}{ Harga } \\
\hline & & & $\begin{array}{c}\text { Produk } \\
\text { Penelitian }\end{array}$ & $\begin{array}{l}\text { Produk } \\
\text { Pohon } \\
\text { Cemara }\end{array}$ & $\begin{array}{l}\text { Produk } \\
\text { Prokon } \\
\text { Concrete } \\
\text { Industry }\end{array}$ & $\begin{array}{c}\text { Produk Alam } \\
\text { Daya Sakti }\end{array}$ \\
\hline 1. & $0 \%$ & 424,167 & Rp 1.466,- & $\operatorname{Rp} 2.111,-$ & Rp 1.896,- & Rp 1.866,- \\
\hline 2. & $5 \%$ & 436,667 & Rp 1.980,- & Rp 2.111,- & Rp 1.896,- & Rp 1.866,- \\
\hline 3. & $10 \%$ & 465 & Rp 1.964,- & Rp 2.111,- & Rp 1.896,- & Rp 1.866,- \\
\hline 4. & $15 \%$ & 523,333 & Rp 1.948,- & $\begin{array}{c}\text { Tidak } \\
\text { Memproduksi }\end{array}$ & $\begin{array}{c}\text { Tidak } \\
\text { Memproduksi }\end{array}$ & $\begin{array}{c}\text { Tidak } \\
\text { Memproduksi }\end{array}$ \\
\hline
\end{tabular}

Setelah dibandingkan harga paving block benda uji pada penelitian ini dengan paving block yang ada di pasaran, ternyata harga paving block yang digunakan pada penelitian ini memiliki harga yang tidak jauh berbeda dengan yang diproduksi di pabrik. Untuk paving block yang tidak mengandung pecahan keramik sama sekali, harga produk penelitian jauh lebih murah dari paving block yang ada di pasaran Kota Semarang. Namun, untuk paving block yang mengandung pecahan keramik, harga produk penelitian lebih murah dari paving block yang diproduksi oleh Pohon Cemara, namun lebih mahal dari paving block produksi Prokon Concrete Industry dan Alam Daya Sakti.

\section{KESIMPULAN DAN SARAN}

\subsection{Kesimpulan}

Kesimpulan dari hasil penelitian dan pembahasan yang sudah dilakukan adalah:

1. Bahan penyusun paving block dalam penelitian ini yaitu semen, pasir, pecahan keramik dan air. Karakteristik untuk material pasir yaitu kadar lumpur 5,13\%, berat jenis 2,79 dan modulus kehalusan 2,65. Dapat diketahui bahwa pasir yang digunakan sedikit melampaui batas karena syarat kadar lumpur maksimal yaitu 5\%, namun untuk berat jenis dan modulus kehalusan telah memenuhi syarat SNI. Sedangkan pada pecahan 
keramik yaitu kadar lumpur 1,63\%, berat jenis 2,4 dan modulus kehalusan 2,9. Nilai tersebut memenuhi syarat sebagai agregat sesuai dengan SNI. Semen yang digunakan dalam keadaan baik dan tidak terdapat gumpalan pada butirannya. Air yang digunakan bersih dan tidak mengandung garam ataupun minyak.

2. Nilai kuat tekan terendah dalam penelitian ini yaitu pada paving block tanpa pecahan keramik dengan komposisi 1: 5 : 0 sebesar 424,167 kg/ $\mathrm{cm}^{2}$. Sedangkan, nilai kuat tekan tertinggi yaitu $523,333 \mathrm{~kg} / \mathrm{cm}^{2}$ pada paving block yang ditambahkan pecahan keramik sebanyak 15\% dengan komposisi $1: 4,25: 0,75$. Nilai kuat tekan tersebut memenuhi persyaratan standar mutu kelas I/A dengan kuat tekan rata-rata $400 \mathrm{~kg} / \mathrm{cm}^{2}$ dan minimal $350 \mathrm{~kg} / \mathrm{cm}^{2}$. Terjadi peningkatan sebesar $23,38 \%$ dari nilai kuat tekan terendah ke nilai kuat tekan yang tertinggi. Maka, dapat dijelaskan bahwa nilai kuat tekan akan meningkat seiring dengan penambahan pecahan keramik.

3. Dilihat dari segi biaya, paving block tanpa campuran pecahan keramik memiliki nilai ekonomis yang paling tinggi yaitu sebesar Rp1.466,- jika dibandingkan paving block dengan campuran keramik yang harganya berkisar Rp 2.000,-. Namun, perlu diketahui juga bahwa terjadi kenaikan nilai kuat tekan yang cukup signifikan dari paving block tanpa campuran pecahan keramik dengan paving block yang diberi pecahan keramik sebanyak $15 \%$, dari $424,167 \mathrm{~kg} / \mathrm{cm}^{2}$ menjadi $523,333 \mathrm{~kg} / \mathrm{cm}^{2}$. Hal itu berarti, walaupun harga paving block dengan campuran keramik 15\% sedikit lebih mahal dari paving block tanpa keramik, namun kualitas yang dihasilkan juga jauh lebih tinggi. Harga paving block hasil penelitian ini juga tidak jauh berbeda dengan harga paving block yang ada di pasaran Kota Semarang.

\subsection{Saran}

Saran yang dapat diberikan dari penelitian yang telah dilakukan adalah

1. Jika kadar lumpur pada material yang digunakan tidak memenuhi syarat, sebaiknya material tersebut dicuci dahulu sebelum digunakan.

2. Pada saat pengujian kuat tekan di laboratorium, permukaan paving block diberi sulfur agar permukaannya menjadi lebih rata.

3. Para produsen dan masyarakat perlu menyadari bahwa bahan tambah dalam proses pembuatan paving block tidak harus berbiaya mahal dan susah didapat, namun sampah berupa pecahan keramik yang bisa didapatkan dengan cuma-cuma juga dapat meningkatkan mutu paving block, serta dapat pula mengurangi sampah yang ada di lingkungan. 
4. Penelitian lanjutan perlu dilakukan karena adanya beberapa keterbatasan dalam penelitian ini, sehingga dianjurkan agar dilakukan:

a. Penambahan berbagai variasi kadar campuran pecahan keramik.

b. Penggunaan perbandingan komposisi air, semen, dan pasir yang berbeda.

c. Dilakukan pengujian tidak hanya pada nilai kuat tekan, namun juga nilai kuat lentur, ketahanan aus, serta penyerapan air agar dapat lebih memahami sifat dari paving block tersebut.

d. Digunakan mesin pencampur adukan paving block berjenis otomatis, karena adukan dapat tercampur lebih baik daripada yang dilakukan secara manual.

\section{DAFTAR PUSTAKA}

Mulyono, T. 2004. Teknologi Beton. Yogyakarta: Andi Publishing.

Pemerintah Kota Semarang. 2014. Peraturan Walikota Semarang Nomor 18 Tahun 2014. Rencana Kerja Pembangunan Daerah (RKPD) Kota Semarang Tahun 2015. Semarang: Pemerintah Kota Semarang.

PUBI. 1982. Persyaratan Umum Bahan Bangunan di Indonesia. Jakarta: Puspen dan Pengembangan Pemukiman.

SNI 03-0691. 1996. Bata Beton (Paving Block). Jakarta: Badan Standardisasi Nasional.

SNI 03-6820. 2002. Spesifikasi Agregat Halus untuk Pekerjaan Adukan dan Plesteran dengan Bahan Dasar Semen. Jakarta: Badan Standardisasi Nasional. 